\title{
Evaluating the Performance of Maize Farmers in Nigeria using Stochastic Distance and Stochastic Production Frontiers
}

\author{
G. C. Aye* and E. D. Mungatana \\ Department of Agricultural Economics, Extension and Rural Development, University of \\ Pretoria, 0002 Pretoria South Africa \\ "E-mail: aye_goody@yahoo.co.uk
}

KEYWORDS Efficiency. Stochastic Frontier. Farmers. Policy. Technology

\begin{abstract}
This study estimates the technical, allocative and cost efficiency of farm households using stochastic distance and stochastic production frontiers. Further, the study examines determinants of efficiency. Data was collected from a random sample of 240 maize farmers in Benue State Nigeria using structured questionnaires. Results from both distance and production frontiers show that farmers in the area are inefficient. Although the efficiency measures from the two frontiers are quantitatively different from each another, the overall consistency check shows that the farm households were ranked similarly by both approaches. This is particularly robust to allocative and cost efficiency. Improved maize seed, inorganic fertilizers, conservation practices, size of farm holdings, education, and access to extension services, credit and market were found to have significant impact on efficiency. Thus, investment in agricultural research coupled with complementary policies is an effective instrument for revamping agriculture and poverty reduction in Nigeria.
\end{abstract}

\section{INTRODUCTION}

Increasing agricultural productivity is considered as one of the major solutions to effectively addressing the current global food crisis. Maize is one of the major staples in Nigeria. The report of a food consumption survey shows that maize was the most often consumed staple, with $20 \%$ of the population eating it at least once a week (International Institute of Tropical Agriculture 2004). Current production is about 8 million tonnes and average yield is 1.5 tonnes per hectare. The average yield is low when compared to the world average of 4.3 tonnes/ha. It is even lower when compared to average yield from other African countries like South Africa, Mauritius and Egypt with average of 2.5 tonnes/ha, 5.8 tonnes/ha and 7.1 tonnes/ha respectively (Food and Agriculture Organization 2009). Thus, there has been a growing gap between the demand for maize and its supply. This necessitated the Federal government in 2006 to initiate a programme of doubling maize production in $\mathrm{Ni}$ geria through the promotion of improved production technologies such as fertilizer, hybrid seeds, pesticides, herbicides and better management practices. Subsequently, other programmes aimed at increasing maize and agricultural productivity has been initiated.

Despite the efforts by the Nigerian government, maize productivity still remains below expectation considering the demonstrated and potential yields of $4.5 \mathrm{t} / \mathrm{ha}$ and above $5.0 \mathrm{t} / \mathrm{ha}$ re- spectively (Remison 2005). The failure to realize increased productivity in the Nigerian maize sector raises questions about the efficiency with which maize farmers use production resources and if inefficiency is observed, could this be attributed to technological innovation and other policy factors? The answer to these policy questions will serve as justification for further investment in maize production and agricultural technology development. There are three main efficiency measures namely technical, allocative and cost efficiency. In microeconomic theory, the primal production frontier describes the maximum output that may be obtained from given inputs. Any deviation from the maximal output is typically considered technical inefficiency. A firm that operates at the production frontier has a technical efficiency of $100 \%$. Even though farmers may be technically efficient, they may not be cost efficient because they are allocatively inefficient. That is, they do not utilise the inputs in optimal proportions, given the observed input prices, and hence do not produce at minimum possible cost. Therefore, the modelling and estimation of both technical and allocative efficiency of agricultural production is often motivated by the need for a more complete representation of economic or cost efficiency of farmers implied by the economic theory of production.

Within the parametric frontier literatures, the traditional approach to answer the sort of empirical questions posed in this study would be to 
estimate a production or cost frontier (see Nigerian studies for example, Ogunyinka and Ajibefun 2004; Umeh and Asogwa 2005; Ogundari et al. 2006; Amaza and Ogundari 2008; Ajibefun 2008; Oyekale and Idjesa 2009). The problem with the direct estimation of cost frontiers is that it will not be practical when input prices do not differ among firms and also not appropriate when there is systematic deviation from cost-minimising behaviour. In this situation, the duality between the cost and production functions breaks down, and the resulting bias in the cost frontier estimates will bias the estimates of cost efficiency (Bauer 1990). The Bravo-Ureta and Riegger (1991) production frontier approach has also been critiqued for simultaneous equation bias (Coelli et al. 2003; Alene and Hassan 2005). These problems with both the production and cost frontiers have motivated recent interest in the use of distance functions in efficiency analysis (Coelli and Perelman 2000; Hailu and Veeman 2000; Morrison-Paul et al. 2000; Coelli et al. 2003; Irz and Thirtle 2004; Alene and Manfred 2005; Herrero 2005; Alene et al. 2006; Solis et al. 2009; Aye and Mungatana 2011) though majority of the studies are limited to technical efficiency. The distance function approach does not require behavioural assumptions to provide a valid representation of the underlying production technology, does not suffer from simultaneous equations bias when firms are cost minimisers or shadow cost minimisers, and does not necessarily require variation in input prices across firms to provide valid estimates of allocative and cost efficiency. Although, distance functions easily accommodates multiple outputs; they are also suitable for single output analysis.

Policy conclusions may vary depending on the methodology used. However, consistency of results from different approaches validates policy conclusions. Against this background, this study employs duality theory in obtaining the parameters of the cost frontier from parametric stochastic input distance function (SIDF) and parametric stochastic frontier production function (SFPF). Subsequently, it analyses smallholder maize farm households' technical, allocative and cost efficiency from these two approaches. The present study is by no means the first to investigate the sensitivity of efficiency estimates to alternative approaches. However, the sensitivity of results to analytical approaches has not been fully explored and results from different studies have been mixed. For instance, Coelli and Perelman (2000) compared results from three specifications of distance functions and two specifications of production frontiers. The study focused on the use of technical efficiency as a measure of performance of the European railways. The results obtained indicate substantial differences in parameter estimates and technical efficiency rankings. Wadud and White (2000) compared data envelopment analysis (DEA) and stochastic frontiers production function (SFPF) measures of the efficiency of 150 rice farmers in two villages in Bangladesh. For the stochastic frontier model both the one-stage and two-stage procedures were implemented. The technical efficiency estimates from SFPF was lower than that from constant returns to scale DEA but greater than that of the variable returns to scale DEA. However, the correlation between different efficiency scores from different methods were positive and significant. Results from both approaches indicate that technical efficiency is significantly influenced by factors measuring environmental degradation and irrigation infrastructure. Estache et al. (2004) applied DEA and econometric methods for performance assessment and ranking of South American electricity units. Specifically they estimated two parametric distance models (an input distance function and an input requirement function) and four deterministic nonparametric DEA models (two input distance functions, one with variable returns to scale and another with constant returns to scale, and two input requirement functions, one with variable returns to scale and another with constant returns to scale). Testing the internal consistency of results obtained from all approaches, first they found that technical efficiency levels from different approaches were significantly different. Secondly, they found high correlation between different econometrics as well as DEA models. However, there was low correlation between DEA and econometrics models. Jaforullah and Premanchandra (2004) estimated technical efficiency for the New Zealand dairy industry using three different estimation techniques under both constant returns to scale and variable returns to scale in production. The approaches used were the SFPF, corrected ordinary least squares (COLS) and DEA. Mean technical efficiency of the industry was found to be sensitive to the choice of estimation technique. In general, the SFPF and DEA 
frontiers resulted in higher mean technical efficiency estimates than the COLS production frontier. Alene and Manfred (2005) compared the performances of the parametric deterministic distance functions (PDF) and DEA with applications to adopters of improved cereal technology in Eastern Ethiopia. Although they found positive and significant correlations between the two approaches, the result from PDF was more robust when analysis was subjected to sensitivity to possible outliers. Herrero (2005) compared four different approaches data envelopment analysis, stochastic production frontier, panel data, and distance function to estimation of technical efficiency of the Spanish Trawl Fishery that was operated in Moroccan water. Their findings show that the efficiency estimates were similar and highly correlated. Thus, they conclude that none of the methodologies can be said to be better than the rest; rather, the most appropriate methodology depends on the characteristics of the production process, the degree of stochasticity, number of outputs and possibility of aggregation. López et al. (2006) used stochastic production frontiers and stochastic distance frontiers to measure technical efficiency for a sample of dairy farms in Abasto Sur, Argentina. Four alternative models were evaluated. Average technical efficiency across the four models ranges from $67.2 \%$ to $88.4 \%$ while the correlation for technical efficiency scores ranges from 0.632 to 0.976 . A key conclusion of their paper is that stochastic production frontiers and stochastic distance frontiers models exhibit similar patterns with respect to the estimated production function parameters; however, the technical efficiency measures were relatively lower for the SDF than SFPF models (67.2\% and $88.4 \%$, respectively). Cuesta et al. (2009) compared the performance of parametric stochastic hyperbolic distance functions with DEA in the analysis of environmental efficiency of U.S. electricity generating units and found that although the means and distributions of the models were significantly different, the ranking of the units by each model is similar.

As is clear from the studies reviewed above, the few efficiency studies comparing results from distance and production frontiers have been limited to technical efficiency only. Therefore, this study extends the previous comparative studies by considering technical, allocative and cost efficiency results from stochastic distance and stochastic production frontiers. To the best of our knowledge, no study has estimated allocative and cost efficiency relative to a stochastic distance and production frontiers using the same data set.

\section{OBJECTIVES OF THE STUDY}

The main objective of this paper is to evaluate the performance of maize farmers in Nigeria using parametric stochastic input distance function (SIDF) and parametric stochastic frontier production function (SFPF). The specific objectives are to: (i) estimate technical, allocative and cost efficiency of maize farmers in Nigeria; (ii) compare efficiency estimates from stochastic distance and stochastic production frontiers; and (iii) examine the impact of policy, technology and socioeconomic variables on technical, allocative and cost efficiency of maize farmers in Nigeria.

\section{METHODOLOGY}

\subsection{Data and Variables}

A multistage stratified sampling procedure was employed in selecting the respondents for this study. A total of 240 farmers were interviewed from four local government areas of Benue State. Data on output and input quantities and prices were collected. The output variable, PROD is the quantity of maize produced during 2008/2009 agricultural season by a farm household and is measured in kilograms. LAND is measured as the area of land in hectares cultivated with maize by a farm household in the relevant period. LABOUR is measured as the amount of both family and hired labour in man-days used by the farm household. FERT is the amount of inorganic fertilizer in kilograms used by the farm household. OTHER is the Fisher quantity index of seed, herbicides and pesticides used by the farm household. Observed average price per unit of inputs used were used in the analysis. $\mathrm{W}_{\text {LAND }}$ is rental price of a hectare of farm land. $\mathrm{W}_{\text {LABOUR }}^{\text {LAND }}$ is price of labour per day. $\mathrm{W}_{\mathrm{FERT}}$ is price of inorganic fertilizer per kilogram. $\mathrm{W}_{\text {OTHER }}$ is an implicit price index of seed, herbicides and pesticides derived by dividing the cost of other inputs by OTHER. All prices were in local currency, Naira. AGE is the age of the household head in years. GENDER is 1 if the household head is a male; 0 oth- 
erwise. EDU is the number of years of formal education completed by the household head. HHS is the number of persons in the household. OFFWORK is 1 for engagement in off-farm work; 0 otherwise. MFG is 1 if the household head is a member of any farmer organization. EXT is the number of extension visits during the cropping period. CREDIT is 1 if farmer had access to credit. MARKET is the distance to the nearest market in km. HYV is the area of maize farm (ha) cultivated with hybrid maize variety. AFERT is the area of maize farm (ha) applied with inorganic fertilizer. HERB is the area of maize farm (ha) subjected to herbicide application. PRACTICES is the number of conservation practices adopted by a farmer on his or her maize farm.

\subsection{Empirical Models}

\subsubsection{Stochastic Input Distance Function and Cost Efficiency Decomposition}

In order to estimate the input distance function in a parametric setting the Cobb-Douglas (CD) functional form is assumed in this study. The specification is admittedly restrictive. However, a likelihood ratio test could not be rejected $\mathrm{CD}$ against the alternative of a translog (TL) form at $5 \%$ level of significance. Moreover, the main advantage of TL is its flexibility, but at the same time its main disadvantage is that it does not easily permit the decomposition of and identification of allocative efficiency as the CD does. For the case of single output, $\mathrm{K}$ inputs, $\mathrm{N}$ farms, the empirical model is specified as:

$$
\ln D_{i}=\delta+\alpha \ln Y_{i}+\sum_{j=1}^{4} \beta_{j} \ln X_{j i}, \quad i=1, \ldots 240,
$$

where $Y_{i}$ is the observed maize output for the $i$ th farmer and $X_{j i}$ is the $j$ th input quantity for the $i$ th farmer, namely land, labour, inorganic fertilizer and Fisher index of other inputs (seed, pesticide and herbicides). In represents the natural logarithm of the associated variables, and $\delta, \alpha$ and $\beta_{j}$ are unknown parameters to be estimated. Imposing the restriction for homogeneity of degree +1 in inputs and representing the resulting unobserved term " $-\ln \mathrm{D}_{\mathrm{i}}$ " as the composed error term, equation (3) becomes:

$$
-\ln X_{k i}=\delta+\alpha \ln Y_{i}+\sum_{j=1}^{4-1} \beta_{j} \ln \left(X_{j i} / X_{k i}\right)+v_{i}-u_{i},
$$

The statistical noise $\left(v_{i}\right)$ is assumed to be iid $N\left(0, \sigma_{v}{ }^{2}\right)$ and independent of the technical inefficiency, $u_{i}$. A likelihood ratio test was conducted to test the hypothesis that $u_{i}$ is halfnormally distributed against the alternative that it has a truncated normal distribution. The hypothesis of half-normal distribution could not be rejected at $5 \%$ level of significance. The technical efficiency scores are predicted using the conditional expectation predictor. The technically efficiency input quantities are obtained as a product of the observed input vector and predicted technical efficiency. From the parameters of the Cobb-Douglas input distance function and, using the first order condition for cost minimisation, the corresponding parameters of the dual cost function are analytically derived and defined as:

$$
\ln C_{i}=b_{0}+\sum_{j=1}^{4} b_{j} \ln W_{j i}+\phi \ln Y_{i}
$$

where $b_{j}=\hat{\beta}_{j}, \phi=-\hat{\alpha}, \quad b_{0}=-\hat{\delta}-\sum_{i=1}^{4} \hat{\beta}_{j} \ln \left(\hat{\beta}_{j}\right)$ and . $C_{i}$ is the cost of production of maize for the $i$ th farmer, $W_{j i}$ is the $j$ th input price vector which includes the price of land, price of labour, price of inorganic fertilizer and implicit price index for other inputs. $Y_{i}$ is the maize output of the $i$ th farmer. $b_{0}, b_{j}$ and $\phi$ are unknown parameters which are derived from the primal function. The cost efficient input quantities are obtained using Shepard's Lemma. Using the observed and minimum cost of production, cost efficiency and allocative efficiency are derived for each farmer.

\subsubsection{Stochastic Frontier Production Function and Cost Efficiency Decomposition}

The Cobb-Douglas stochastic frontier production function is assumed for this study and specified as:

$$
\ln Y_{i}=\delta+\sum_{j=1}^{4} \beta_{j} \ln X_{j i,}+v_{i}-u_{i}
$$

All variables are as defined for the SIDF model. $\delta$ and $\beta^{\prime} s$ are parameters to be estimated. The parameters of the SFPF were estimated using the maximum likelihood method. The observed output of the $i$ th farm, $Y_{i}$, is adjusted for statistical noise by subtracting $v_{i}$ from both sides of the equation (4):

$$
Y_{i}^{*}=Y_{i}-v_{i}=f\left(X_{i} ; \beta\right)-u_{i}
$$

where $Y_{i}^{*}$ is the adjusted output. The technically efficient input vector, for a given level of is derived by solving simultaneously equation (5) and the input ratios, $X_{1} / X_{k}=\rho_{k}(k>1)$, where $\rho_{k}$ is the ratio of the observed inputs. Given the vector of input prices for the $i$ th farm household 
$\left(W_{j i}\right)$, parameter esti mates of the $\operatorname{SFPF}(\hat{\beta})$ in equation (4), and the input oriented adjusted output level in equation (5), the corresponding Cobb-Douglas dual cost frontier is derived and written as

$$
\begin{aligned}
& \ln C_{i}=b_{0}+\sum_{j=1}^{4} b_{j} \ln W_{j i}+\phi \ln Y_{i}^{*} \\
& \text { where } \left.\left.\phi=\left(\sum_{-1}^{+} \hat{\beta}\right)^{-1}, b=\phi \hat{\beta}_{j}, \quad b_{0}=\ln \frac{1}{\phi}-\phi \hat{\delta}+\ln \Pi \hat{\beta}^{\hat{\theta}}\right)\right)
\end{aligned}
$$

The cost efficient input vector is derived by using Shephard's Lemma and then substituting the firm's input prices and adjusted output quantity into the system of demand equations. Using the technically efficient, cost efficient and actual costs of production, technical allocative and cost efficiency are calculated for each farmer (Bravo-Ureta and Rieger 1991).

\subsubsection{Technology and Policy Impacts on Efficiency}

To analyse the impact of technological innovation and other policy variables on technical, allocative and cost efficiency a second stage procedure is used whereby the efficiency scores obtained from the first stage are regressed on the selected explanatory variables using a double-bounded Tobit model. The one stage procedure would have been preferable in the case of technical efficiency since the stochastic frontier is estimated under the assumption that the technical inefficiency effects are identically distributed (Battese and Coelli 1995). However, allocative and cost efficiency are derived, not estimated, hence, a one stage procedure cannot be implemented for them. Therefore, the two stage procedure is followed in this study to ensure uniformity and consistency in the interpretation of results from all the three measures of efficiency. The inclusion of technology innovation variables in an efficiency model presents the problem of potential endogeneity and self selectivity. The exogeneity of these variables were tested using the instrumental variable approach as proposed by Smith and Blundell (1986). To correct for endogeneity, this study follows a two step approach, in which each endogenous technology variable is estimated in a first stage and their predicted values are included in a second step as additional explanatory variables which yields unbiased estimates of the impact of technological innovation on efficiency.

\section{RESULTS AND DISCUSSION}

\subsection{ML and OLSEstimates of the SIDF and SFPF} Models

Table 1 presents both the maximum likelihood (ML) and the ordinary least square (OLS) estimates of the SIDF and SFPF. Results show that all variables are significant at 1 per cent and have expected signs in both SIDF and SFPF. The estimated coefficient of output in the SIDF is less than one in absolute terms, indicating increasing returns to scale. It should be stressed here that the homogeneity restriction on the input coefficients of the SIDF does not translate to constant returns to scale, as is the case with the conventional production frontier. The returns to scale for SIDF was computed as the inverse of the negative of the output coefficient (Coelli et al. 2005). Similarly, the SFPF indicated increasing returns to scale, but this was computed as the sum of the input coefficients. The partial output elasticity of land is 0.67 and 0.82 in the SIDF and SFPF respectively and is the largest among the inputs thereby depicting the importance of land in the household production. It implies that a $10 \%$ increase in land size would increase output by 6.7 and $8.2 \%$ respectively in the SIDF and SFPF models. This finding confirms the observation of this study, that the share of expenditure on land in the cost of production of sampled farmers is highest among other inputs. Land is the scarcest input and the high marginal returns to land are a reflection of the very small size of plot many farmers are constrained to cultivate. The least contributor to household production is other inputs.

The estimate of the variance parameter, in the SIDF and SFPF models is 0.83 and 0.84 respectively. These are significant at $1 \%$ implying that $83-84 \%$ of the total variation in output is due to inefficiency, that is, the technical inefficiency effects are significant in both models. This result is confirmed by conducting a likelihood ratio test, to test the hypothesis of OLS versus SIDF and OLS versus SFPF. In each case, the adequacy of the OLS model in representing the data was rejected. Based on the estimated parameters of the SIDF, the parameters of the corresponding dual cost function as specified in equation (3) were derived and this formed the basis of computing the cost and allocative efficiency. The dual cost frontier is given as:

$\ln C_{i}=-2.977+0.667 \ln W_{\text {Iexd }}+0.233 \ln W_{\text {Labour }}+0.038 W_{\text {Fert }}$ $+0.061 \ln W_{\text {Other }}+0.740 \ln P R O D_{i}$ 
Table 1: The MLE and OLS estimates of the SIDF and SFPF

\begin{tabular}{|c|c|c|c|c|c|}
\hline \multirow[t]{2}{*}{ Variables } & \multirow[t]{2}{*}{ Mean } & \multicolumn{2}{|c|}{$S I D F$} & \multicolumn{2}{|c|}{$S F P F$} \\
\hline & & $O L S$ & $M L E$ & $O L S$ & $M L E$ \\
\hline INTERCEPT & - & $\begin{array}{l}3.718^{* * *} \\
(0.200)\end{array}$ & $\begin{array}{l}3.883^{* * *} \\
(0.216)\end{array}$ & $\begin{array}{l}5.623^{* * *} \\
(0.140)\end{array}$ & $\begin{array}{l}5.908^{* * *} \\
(0.145)\end{array}$ \\
\hline PROD & 1320.38 & $\begin{array}{l}-0.729^{\text {****** }} \\
(0.021)\end{array}$ & $\begin{array}{l}-0.740^{\text {**** }} \\
(0.021)\end{array}$ & (1) & \\
\hline LAND & 1.208 & $\begin{array}{l}0.679^{* * * *} \\
(0.022)\end{array}$ & $\begin{array}{l}0.667^{* * * *} \\
(0.024)\end{array}$ & $\begin{array}{l}0.820^{* * * *} \\
(0.031)\end{array}$ & $\begin{array}{l}0.838^{* * *} \\
(0.027)\end{array}$ \\
\hline LAB & 111.195 & $\begin{array}{l}0.219^{* * * *} \\
(0.021)\end{array}$ & $\begin{array}{l}\left.0.233^{* * * *}\right) \\
(0.023)\end{array}$ & $\begin{array}{l}0.216^{* * * *} \\
(0.029)\end{array}$ & $\begin{array}{l}0.192^{* * * *} \\
(0.029)\end{array}$ \\
\hline FERT & 115.185 & $\begin{array}{l}0.036^{* * * *} \\
(0.003)\end{array}$ & $\begin{array}{c}0.038^{* * *} \\
(0.003)\end{array}$ & $\begin{array}{c}\left.0.048^{* * * *}\right) \\
(0.004)\end{array}$ & $\begin{array}{l}0.050^{* * * *} \\
(0.004)\end{array}$ \\
\hline OTHER & 56.343 & 0.067 & $0.061^{\mathrm{a}}$ & $\begin{array}{l}0.056^{* * *} \\
(0.011)\end{array}$ & $\begin{array}{l}0.056^{* * * *} \\
(0.010)\end{array}$ \\
\hline \multicolumn{2}{|c|}{ SIGMA-SQUARED } & & $\begin{array}{l}0.043^{* * *} \\
(0.006)\end{array}$ & $\begin{array}{l}0.067^{* * *} \\
(0.009)\end{array}$ & \\
\hline \multicolumn{2}{|l|}{ GAMMA } & & $\begin{array}{l}0.825^{* * *} \\
(0.060)\end{array}$ & & $\begin{array}{l}0.837^{\text {**** }} \\
(0.051)\end{array}$ \\
\hline \multirow{2}{*}{\multicolumn{2}{|c|}{$\begin{array}{l}\text { LLF } \\
\text { Returns to scale }\end{array}$}} & 125.479 & 132.274 & 72.044 & 81.100 \\
\hline & & & 1.351 & & 1.136 \\
\hline
\end{tabular}

${ }^{* * *}$ Significant at $1 \%$ level. Standard errors are shown in parenthesis. ${ }^{a}$ The estimate of $\beta_{4}$ is computed by the homogeneity condition

where $\mathrm{C}$ is the cost of production for the $i$ th farmer. is the rental price of land per hectare estimated at $\mathrm{N} 4989.17$. is the price of labour per day estimated at $\mathrm{N} 89.81$. is the price of inorganic NPK fertilizer per $\mathrm{kg}$ estimated at. $\mathrm{N57.9}$. is implicit price index of other inputs estimated at N68.64 per $\mathrm{kg}$. The derived cost function is equally well behaved.

Similarly, based on the estimated parameters of the SFPF, the input ratios, and the adjusted observed output levels, the parameters of the corresponding dual cost function were derived and this formed the basis of computing the cost and allocative efficiency. The dual cost frontier is given as:

$\ln \mathrm{C}_{\mathrm{i}}=-4.390+0.738 \ln \mathrm{W}_{\mathrm{Land}}+0.169 \ln \mathrm{W}_{\mathrm{Labor}}$

$+0.044 \mathrm{~W}_{\text {Fert }}+0.049 \ln \mathrm{W}_{\text {Other }}+0.880 \ln \operatorname{PROD}_{\mathrm{i}}(8)$

where the variables are as defined above for the cost function derived from the SIDF.

\subsection{Comparison of SIDF and SFPF Efficiency Estimates and Distributions}

The results of efficiency distributions and some descriptive statistics from the SIDF and SFPF are presented in Table 2. For the SIDF, technical efficiency ranges from 64.3 to 97.1 with a mean of $86.7 \%$. This implies that if farm households will operate on the frontier, they will achieve a cost savings of $13.3 \%$ without reduc- ing output. On the other hand, if the average farm household in the sample was to achieve the technical efficiency level of its most efficient counterpart, then the average farm household could realize a $10.7 \%$ cost savings (that is, 1[86.7/97.1]). A similar calculation for the most technically inefficiency farm household reveals cost saving of $33.7 \%$ (that is, 1- [64.3/97.1]). Technical efficiency from the SFPF ranges from 43.3 to 99.7 with a mean of $85.3 \%$. Here, the presence of technical inefficiency indicates potential output gains without increasing input use. This implies that if farm households were to operate on the production frontier, they will achieve a cost savings of $14.7 \%$. Similar high technical efficiency scores were obtained by Alene et al. (2006).

The average allocative efficiency from the SIDF model is $57.8 \%$ with a low of $23 \%$ and a high of $88.8 \%$. This implies that there is room to improve allocative efficiency of the farm households by $42.2 \%$, if they operate on the frontier. It also suggests that if the average farm household was to achieve the allocative efficiency level of its most efficient farm household, then the average farm household could achieve a cost saving of $34.9 \%$ while the least efficient farm household would achieve a cost saving of $74 \%$. The average allocative efficiency from the SFPF is $52.6 \%$ with a low of $22.9 \%$ and a high of $79.9 \%$ 
Table 2: Estimates and distribution of efficiency from SIDF and SFPF

\begin{tabular}{|c|c|c|c|c|c|c|}
\hline \multirow[t]{2}{*}{ Efficiency level (\%) } & \multicolumn{3}{|c|}{$S I D F$} & \multicolumn{3}{|c|}{$S F P F$} \\
\hline & $T E$ & $A E$ & $C E$ & $T E$ & $A E$ & $C E$ \\
\hline$\leq 40$ & 0 & 21 & 55 & 0 & 34 & 88 \\
\hline$\overline{4} 1-50$ & 0 & 37 & 59 & 1 & 77 & 72 \\
\hline $51-60$ & 0 & 68 & 73 & 2 & 67 & 70 \\
\hline $61-70$ & 14 & 84 & 44 & 27 & 48 & 10 \\
\hline $71-80$ & 29 & 28 & 8 & 51 & 14 & 0 \\
\hline $81-90$ & 111 & 2 & 1 & 73 & 0 & 0 \\
\hline $91-100$ & 86 & 0 & 0 & 86 & 0 & 0 \\
\hline Mean & 86.7 & 57.8 & 50.3 & 85.3 & 52.6 & 44.6 \\
\hline Min & 64.3 & 23.0 & 19.6 & 43.3 & 22.9 & 15.8 \\
\hline Max & 97.1 & 88.8 & 85.9 & 99.7 & 79.9 & 69.6 \\
\hline SD & 7.6 & 11.9 & 12.0 & 10.7 & 11.9 & 10.8 \\
\hline $\mathrm{CV}$ & 8.8 & 20.5 & 23.9 & 12.5 & 22.6 & 24.2 \\
\hline
\end{tabular}

Min = Minimum $;$ Max = Maximum $;$ SD = Standard deviation $; \mathrm{CV}=$ Coefficient of variation; $\mathrm{TE}=\mathrm{Technical}$ Efficiency; $\mathrm{AE}=$ Allocative Efficiency; $\mathrm{CE}=$ Cost Efficiency

which implies that allocative efficiency of the farm households can be improved by $47.4 \%$ through appropriate policy interventions. The mean allocative efficiency reported for each of the models indicates that some inputs are being used in incorrect proportions. To check for overutilization or under-utilization of the production inputs by farmers, the ratio of the technically efficient input quantity over the cost-efficient input quantity (for each observation) is calculated for each of the frontier models. For the SIDF, the mean ratio is $0.61,2.86,0.46$ and 4.71 for land, labour, fertilizer and other inputs respectively. For the SFPF the corresponding values are $0.72,5.20,0.63$ and 0.10 . This implies that given the respective market prices of the various inputs, fertilizer is consistently being under-utilized, labour is consistently over-utilized, land is under-utilized in most cases whereas results of other inputs are mixed. Therefore, for the farmers to operate efficiently, the use of fertilizer and land needs to be increased whereas the use of labour needs to be contracted.

The cost efficiency from the SIDF model ranges from 19.6 to 85.9 with a mean of $50.3 \%$ giving room for cost efficiency improvement by $49.7 \%$, if farm households were to operate on the frontier and also suggests a gain economic efficiency of $41.5 \%$ for the average farm household and $77.2 \%$ for the least efficient farm household. cost efficiency from the SFPF model ranges from 15.8 to 69.6 with a mean of $44.6 \%$ giving room for overall improvement in efficiency by $55.4 \%$. The two approaches have demonstrated that maize farmers in Benue State operate with considerable inefficiency dominated by cost inefficiency. This provides an avenue for policy interventions that would help reduce inefficiency. It is observed that the estimated technical, allocative and cost efficiency from the distance frontier are greater than those from the production frontier. Similarly, the efficiency scores from the SIDF model are less variable than those from SFPF. A formal test was conducted to evaluate the statistical significance of the difference between the SIDF and SFPF technical, allocative and cost efficiency scores. This was achieved by testing different complementary hypotheses relative to: (i) the equality of means (t-test), (ii) the equality of distributions (Wilcoxon signed rank-test), and (iii) the independence of the results with regard to their rank (Spearman's correlation test).

Table 3 presents the results, concluding that in the case of the t-tests, the differences between the SIDF and SFPF efficiency scores are statistically significant with a confidence of 95

Table 3: Tests of hypotheses between SIDF and SFPF efficiency scores

\begin{tabular}{cccc}
\hline & $\begin{array}{l}\text { T-test- } \\
\text { t-stati- } \\
\text { stic }\end{array}$ & $\begin{array}{l}\text { Wilcoxon } \\
\text { test } \\
\text { Z-statistic }\end{array}$ & $\begin{array}{l}\text { Spear- } \\
\text { man's } \\
\text { Rho } \rho\end{array}$ \\
\hline Technical & 1.623 & 1.164 & -0.020 \\
efficiency & $(0.106)$ & $(0.245)$ & $(0.755)$ \\
Allocative & $10.640^{* * *}$ & $8.929^{* * *}$ & $0.772^{* * *}$ \\
efficiency & $0.000)$ & $(0.000)$ & $(0.000)$ \\
Cost & $23.842^{* *}$ & $13.393^{* * *}$ & $0.957^{* * *}$ \\
efficiency & $(0.000)$ & $(0.000)$ & $(0.000)$ \\
\hline
\end{tabular}

${ }^{* * * *}$ Significantly different from zero at $5 \%$ level; pvalues in parenthesis 
per cent. The Wilcoxon test further reinforces this result by indicating that the distributions are also statistically different. Although the different approaches produced efficiency measures that are quantitatively different from each another, it is still possible to achieve consistency of results with respect to the ranking of individual farm households, which in many policy analyses may be more important than the quantitative estimates of efficiency. Therefore, to assess the overall consistency of the two methods in ranking individual farms in terms of efficiency, the coefficient of Spearman's rank-order correlation was calculated between the two models. Spearman's correlation suggests that the different farm households rank similarly when they are ordered according to either their SIDF or SFPF efficiency scores. Based on this, one can draw valid policy conclusions from the results of this study especially with respect to allocative and cost efficiency.

\subsection{Policy Impacts on Technical, Allocative and Cost Efficiency of Maize Farmers}

Smith-Blundel test of exogeneity was conducted on the technological innovation variables. It was observed that the exogeneity of each variable in each model was rejected in at least one case. Detailed results are available from the authors upon request. An endogeneity-corrected Tobit model was employed in the second-step regression in the case of rejection of the null hypothesis. The results of the secondstage endogeneity-corrected Tobit model are presented in Table 4. The significance of the likelihood ratio (LR) test in each model implies the joint significance of all variables included in

Table 4: Tobit model results of impact of policy factors on TE, AE and CE

\begin{tabular}{|c|c|c|c|c|c|c|c|}
\hline \multirow[t]{2}{*}{ Variable } & \multirow[t]{2}{*}{ Mean } & \multicolumn{3}{|c|}{ SIDF } & \multicolumn{3}{|c|}{$S F P F$} \\
\hline & & TECoeff & AECoeff & CECoeff & TECoeff & AECoeff & CECoeff \\
\hline Gender & 0.888 & $\begin{array}{l}-0.013 \\
(0.009)\end{array}$ & $\begin{array}{c}0.012 \\
(0.019)\end{array}$ & $\begin{array}{c}0.000 \\
(0.017)\end{array}$ & $\begin{array}{l}-0.017 \\
(0.018)\end{array}$ & $\begin{array}{c}0.016 \\
(0.018)\end{array}$ & $\begin{array}{r}.003 \\
(0.015)\end{array}$ \\
\hline Age & 47.167 & $\begin{array}{l}0.002^{* * * *} \\
(0.000)\end{array}$ & $\begin{array}{l}-0.000 \\
(0.001)\end{array}$ & $\begin{array}{c}0.001 \\
(0.001)\end{array}$ & $\begin{array}{l}0.002^{* * * *} \\
(0.001)\end{array}$ & $\begin{array}{c}0.001 \\
(0.001)\end{array}$ & $\begin{array}{r}0.000 \\
(0.001)\end{array}$ \\
\hline Edu & 8.433 & $\begin{array}{l}0.002^{* * * *} \\
(0.000)\end{array}$ & $\begin{array}{c}0.000 \\
(0.001)\end{array}$ & $\begin{array}{c}0.001 \\
(0.001)\end{array}$ & $\begin{array}{r}0.002^{*} \\
(0.001)\end{array}$ & $\begin{array}{c}0.001 \\
(0.001)\end{array}$ & $\begin{array}{r}0.000 \\
(0.001)\end{array}$ \\
\hline Hhs & 11.742 & $\begin{array}{l}0.001^{* * * *} \\
(0.000)\end{array}$ & $\begin{array}{c}0.001 \\
(0.001)\end{array}$ & $\begin{array}{c}0.001^{*} \\
(0.001)\end{array}$ & $\begin{array}{l}0.002^{* * * *} \\
(0.001)\end{array}$ & $\begin{array}{c}0.003 \\
(0.001)\end{array}$ & $\begin{array}{c}0.001^{*} \\
(0.001)\end{array}$ \\
\hline Land & 1.208 & $\begin{array}{l}-0.034^{* * * *} \\
(0.008)\end{array}$ & $\begin{array}{c}0.045^{* *} \\
(0.020)\end{array}$ & $\begin{array}{c}0.025 \\
(0.018)\end{array}$ & $\begin{array}{l}0.098^{* * * * *} \\
(0.018)\end{array}$ & $\begin{array}{c}0.012 \\
(0.020)\end{array}$ & $\begin{array}{r}0.055 \\
(0.016)\end{array}$ \\
\hline Offwork & 0.675 & $\begin{array}{l}-0.010^{*} \\
(0.006)\end{array}$ & $\begin{array}{l}-0.005 \\
(0.013)\end{array}$ & $\begin{array}{l}-0.009 \\
(0.012)\end{array}$ & $\begin{array}{l}-0.000 \\
(0.012)\end{array}$ & $\begin{array}{l}-0.007 \\
(0.012)\end{array}$ & $\begin{array}{l}-(0.010) \\
-(0.010)\end{array}$ \\
\hline Mfg & 0.454 & $\begin{array}{l}0.045^{\text {***** }} \\
(0.010)\end{array}$ & $\begin{array}{c}0.002 \\
(0.021)\end{array}$ & $\begin{array}{c}0.028 \\
(0.019)\end{array}$ & $\begin{array}{c}0.009 \\
(0.021)\end{array}$ & $\begin{array}{c}0.031) \\
(0.020)\end{array}$ & $\begin{array}{r}0.027^{*} \\
(0.017)\end{array}$ \\
\hline Ext & 2.546 & $\begin{array}{l}-0.003^{* *} \\
(0.002)\end{array}$ & $\begin{array}{c}0.007^{*} \\
(0.004)\end{array}$ & $\begin{array}{c}0.004) \\
(0.003)\end{array}$ & $\begin{array}{c}0.005 \\
(0.003)\end{array}$ & $\begin{array}{l}-0.002 \\
(0.003)\end{array}$ & $\begin{array}{r}0.001 \\
(0.003)\end{array}$ \\
\hline Credit & 0.138 & $\begin{array}{l}0.023^{* * * *} \\
(0.008)\end{array}$ & $\begin{array}{l}0.129^{* * * *} \\
(0.018)\end{array}$ & $\begin{array}{c}0.130^{* * *} \\
(0.016)\end{array}$ & $\begin{array}{c}0.059^{* *} \\
(0.017)\end{array}$ & $\begin{array}{l}0.075^{* * * *} \\
(0.017)\end{array}$ & $\begin{array}{l}0.101^{* * * *} \\
(0.014)\end{array}$ \\
\hline Market & 6.278 & $\begin{array}{l}-0.000 \\
(0.000)\end{array}$ & $\begin{array}{l}-0.000 \\
(0.001)\end{array}$ & $\begin{array}{l}-0.000 \\
(0.001)\end{array}$ & $\begin{array}{l}-0.002^{* *} \\
(0.001)\end{array}$ & $\begin{array}{l}-0.001 \\
(0.001)\end{array}$ & $\begin{array}{r}-0.001 \\
-(0.001)\end{array}$ \\
\hline Hyv & 0.895 & $\begin{array}{c}0.011^{* *} \\
(0.006)\end{array}$ & $\begin{array}{l}0.034^{* * * *} \\
(0.013)\end{array}$ & $\begin{array}{l}0.035^{* * * *} \\
(0.011)\end{array}$ & $\begin{array}{c}0.010 \\
(0.012)\end{array}$ & $\begin{array}{r}0.027^{*} \\
(0.011)\end{array}$ & $\begin{array}{c}0.032^{* * * * *} \\
(0.010)\end{array}$ \\
\hline Afert & 0.816 & $\begin{array}{c}0.018^{* *} \\
(0.009)\end{array}$ & $\begin{array}{c}0.057^{* *} \\
(0.027)\end{array}$ & $\begin{array}{l}0.060^{* * * *} \\
(0.024)\end{array}$ & $\begin{array}{c}0.025 \\
(0.017)\end{array}$ & $\begin{array}{l}0.098^{* * * *} \\
(0.025)\end{array}$ & $\begin{array}{l}0.065^{* * * *} \\
(0.021)\end{array}$ \\
\hline Herb & 0.591 & $\begin{array}{c}0.008 \\
(0.006)\end{array}$ & $\begin{array}{l}-0.014 \\
(0.013)\end{array}$ & $\begin{array}{l}-0.005 \\
(0.008)\end{array}$ & $\begin{array}{l}-0.048^{* * * *} \\
(0.009)\end{array}$ & $\begin{array}{l}0.023^{* * * *} \\
(0.008)\end{array}$ & $\begin{array}{r}-0.004 \\
-(0.007)\end{array}$ \\
\hline Practices & 1.75 & $\begin{array}{l}0.009^{* * * *} \\
(0.002)\end{array}$ & $\begin{array}{c}0.002 \\
(0.005)\end{array}$ & $\begin{array}{c}0.006 \\
(0.004)\end{array}$ & $\begin{array}{c}0.005 \\
(0.004)\end{array}$ & $\begin{array}{c}0.001 \\
(0.004)\end{array}$ & $\begin{array}{r}0.003 \\
(0.004)\end{array}$ \\
\hline Intercept & & $\begin{array}{l}0.750^{* * * *} \\
(0.019)\end{array}$ & $\begin{array}{l}0.4311^{* * * *} \\
(0.041)\end{array}$ & $\begin{array}{l}0.305^{* * * *} \\
(0.038)\end{array}$ & $\begin{array}{l}0.726^{* * *} \\
(0.040)\end{array}$ & $\begin{array}{l}0.359^{* *} \\
(0.039)\end{array}$ & $\begin{array}{r}0.256 \\
(0.033)\end{array}$ \\
\hline $\begin{array}{l}\text { LLF } \\
\text { LR Test }\end{array}$ & & 417.474 & 234.686 & 259.949 & $\begin{array}{l}241.167 \\
101970^{* * * *}\end{array}$ & $\begin{array}{l}246.962 \\
163400^{* * * *}\end{array}$ & $\begin{array}{r}291.303 \\
\end{array}$ \\
\hline
\end{tabular}

${ }^{* * *}$ Significant at $1 \%$ level; ${ }^{* *}$ Significant at $5 \%$ level; *Significant at $10 \%$ level. Standard errors are shown in parenthesis. 
the model. Thus, the hypothesis that the technology and other policy variables included in each model have no significant impact on efficiency is rejected.

The effect of age could be positive or negative. AGE had a positive sign and significant impact on technical efficiency in the two models. Thus, the variable indexes experience and serve as a proxy for human capital showing that farmers with greater farming experience will have better management skills and thus higher efficiency than younger farmers. Increased farming experience may lead to better assessment of the importance and complexity of good farming decision, including efficient use of farming inputs. The second human capital variable, EDU was consistently positive though has significant impact on only the technical efficiency case only. Similar positive and significant impact of education on -technical efficiency of maize farmers in Nigeria was found by Oyewo and Fabiyi (2008).

HHS was found to be positively and significantly related to technical and cost efficiency in the two models. A possible reason for this result might be that a larger household size guarantees the availability of family labour for farm operations to be accomplished in time. The variable LAND is aimed at capturing the effect of scale production on efficiency. A review by Lundvall and Battese (2000) establish a varied relationship between farm size and technical inefficiency in developing countries using the frontier production function. In this study, it is observed that the in most cases, LAND had a positive effect on the three efficiency measures. It then appears that small-scale operations are a source of inefficiency and hence low productivity in the area. These results are consistent with the findings of Karagiannis et al. (2000).

OFFWORK can increase productivity by producing income that can be used to purchase modern inputs. Here, it was consistently negative but with a significant impact on technical efficiency only in the SIDF. This implies that farmers who engage in off-farm work are likely to be less efficient in farming. Productivity suffers when any part of production is neglected. This finding is consistent with that of Mariano et al. (2010).

Membership of a farmers' group (MFG) indexes social capital and affords farmers the opportunity to share information on modern maize practices by interacting with others. It also pro- vides them with bargaining power in the input, output and credit markets. As expected, MFG was found to be consistently positive, but with a significant impact on technical and -cost efficiency in the SIDF and SFPF respectively. Extension (EXT) is expected to be positive as it enhances farmers' access to information and improved technological packages. However the impact of the extension variable here is mixed. It had a negative and significant impact on technical efficiency but positive and significant impact on allocative efficiency in the SIDF. It could be that when extension agents do not have new information for farmers, contact with those agents would only amount to a waste of resources, leading to a negative impact. This finding is consistent with the findings of Haji (2006) and Demircan et al. (2010).

CREDIT is consistently positive and significant. This is as expected since the availability of credit loses the production constraints thus facilitating timely purchase of inputs and therefore increases productivity via efficiency. The result is consistent with the findings of Muhammad (2009). The variable MARKET serves as a proxy for the development of road and market infrastructures. It is generally believed that farms located closer to the market are more technically, allocatively and economically efficient than the farms located farther from the market as this might not only increase production cost but also affect farming operations, especially the timing of input application. This expectation was satisfied in this study as the MARKET variable was correctly signed in most cases but it was only had significant impact on technical efficiency in the SFPF

Although improved technologies will generally raise production cost in absolute terms, the yield enhancement arising from their usage can reduce per unit cost of production thereby raising not only technical efficiency but cost efficiency as well. Results show that HYV had positive and significant impact on technical, allocative and cost efficiency in almost all cases. Chirwa (2007) employed a production frontier model and found a positive and significant impact of hybrid seed use on technical efficiency of smallholder maize farmers in Malawi. Similar impact of improved maize seed on cost efficiency from a cost frontier model was reported in Zavale et al. (2006). These findings further strengthen the need for hybrid seed improve- 
ment and diffusion in Nigeria in line with the current doubling of maize production programme of the federal government.

AFERT had positive and significant impact on allocative and cost efficiency in the two models. Its impact on technical efficiency was only significant in the SIDF. Msuya et al. (2008) who found a positive impact of inorganic fertilizer on allocative and technical efficiency, respectively. Thus, failure to use fertilizer may result in irretrievable output loss. The sign of the variable, HERB, is mixed though negative in most cases. The dominating negative sign of herbicides could be due to the farmers' perception of the health and environmental effects of herbicides coupled with its high cost and inadequate application knowledge, which constrained its adoption and usage. The use of conservation practices improves land quality and hence yield as well as reduces the unit cost of production. As expected, PRACTICES have positive impact on all the efficiency measures in the two models though this impact was only significant for technical efficiency. This is consistent with Solis et al. (2009) result for the case of technical efficiency. Therefore, economic and environmental sustainability should be viewed as complementary rather than competitive goals.

\section{CONCLUSION}

A number of agricultural policies and or initiatives have been put in place to foster the growth of maize in Nigeria. However, productivity still remained low. This study evaluates the technical, allocative and cost efficiency of farm households using stochastic distance and production function frontiers. Based on the findings of this study, resources are not efficiently used by maize farmers as was evidenced by both the stochastic distance and production function frontiers. The differences between the SIDF and SFPF efficiency scores are statistically significant with a confidence of 95 per cent. The Wilcoxon test further reinforces this result by indicating that the distributions are also statistically different. Although the different approaches produced efficiency measures that are quantitatively different from each another, the overall consistency check shows that the farm households were ranked similarly by both approaches. This is particularly robust to allocative and cost efficiency. The study also examined factors which might affect technical, allocative and cost efficiency. Result indicates that limited use of modern technologies such as improved maize seed, inorganic fertilizers and conservation practices, smallness of farm holdings, inadequate formal education, access to extension services, credit and market were significant determinants of efficiency.

\section{RECOMMENDATIONS}

The positive and significant impact of hybrid seed calls for the Nigerian government to invest more in research and development that will produce a viable seed sector in the country. Greater availability and accessibility of inorganic fertilizers is very crucial as these could enhance the efficiency of smallholder farmers. This was also evidenced in the under-utilization of fertilizer as a production input. Given the escalating prices of inorganic fertilizers, alternatives such as soil conservation practices which reduce the effective costs of soil fertility management options are necessary. This should essentially form an important extension package to all farmers since the goal of economic benefits and environmental sustainability must be balanced. In view of the interactions among the agricultural technology packages, it is argued that adoption of the whole package would be more profitable than adopting a component or some components of the technology package. From these findings, a further investment in agricultural research and development is necessary for increasing efficiency and productivity of maize production and subsequently reducing food insecurity and poverty alleviation in Nigeria.

Appropriate policy formulation and implementation is an effective instrument to improvement in farm efficiency and productivity which promotes overall growth of the economy. Although, the promotion of improved technologies is an important instrument in increasing agricultural productivity, it is not sufficient to make the needed necessary impacts on rural livelihood and the economy at large. Therefore, complementary policies which include investment in education, land expansion, improvement in the extension system, efficient credit delivery system including access to credit from both micro-credit and commercial banks and enabling market oriented policies must also form part of the strategy. Finally, concerted efforts aimed at 
removing the bottlenecks that have constrained effective policy implementation and its accrued benefits in the Nigerian agriculture are needed from all the stake holders.

\section{ACKNOWLEDGEMENTS}

The authors are grateful to DAAD and MMMF for funding this study.

\section{REFERENCES}

Ajibefun IA 2008. An evaluation of parametric and non-parametric methods of technical efficiency measurement: Application to small scale food crop production in Nigeria. Journal of Agriculture and Social Sciences, 4(3): 95-100.

Alene DA, Hassan RM 2005. The efficiency of traditional and hybrid maize production in eastern Ethiopia: Extended efficiency decomposition approach. Journal of African Economies, 15(1): 91116.

Alene DA, Manfred Z 2005. Technology adoption and farmer efficiency in multiple crops production in eastern Ethiopia: A comparison of parametric and non-parametric distance functions. Agricultural Economics Review, 6(1): 5- 19

Alene DA, Manyong VM, Gockowski J 2006. The production efficiency of intercropping annual and perennial crops in southern Ethiopia: A comparison of distance functions and production frontiers. Agricultural Systems, 91: 51-70.

Amaza PS, Ogundari K 2008. An investigation of factors that influence the technical efficiency of soybean production in the guinea savannas of Nigeria. Journal of Food, Agriculture and Environment, 6(1): 92-96.

Aye GC, Mungatana ED 2011. Technological innovation and efficiency in the Nigerian maize sector: parametric stochastic and non-parametric distance function approaches, Agrekon, 50(4): 1-24.

Battese GE, Coelli TJ 1995. A model for technical inefficiency effects in a stochastic frontier production function for panel data. Empirical Economics, 20: 325-332.

Bauer PW 1990. Recent developments in the econometric estimation of frontiers. Journal of Econometrics, 46: 39-56.

Bravo-Ureta BE, Rieger L 1991. Dairy farm efficiency measurement using stochastic frontiers and neoclassical duality. American Journal of Agricultural Economics, 73(2): 421-428.

Chirwa EW 2007. Sources of Technical Efficiency among Smallholder Maize Farmers in Southern Malawi. AERC Research Paper, 172.

From <http://www.aercafrica.org/documents/ RP172.pdf> (Retrieved April 2, 2009).

Coelli TJ, Perelman S 2000. Technical efficiency of European railways: A distance function approach. Applied Economics, 32: 1967-1976.

Coelli T, Fleming E, Singh S 2003. An Input Distance Function Approach to the Measurement of Techni- cal and Allocative Efficiency. Paper presented at the $8^{\text {th }}$ European Workshop on Efficiency and Productivity Analysis, Oviedo, Spain, September 24 to $27,2003$.

Coelli T, Prasada Rao DS, Battese GE 2005. An Introduction to Efficiency and Productivity Analysis. $2^{\text {nd }}$ Edition. Kluwer Academic Publishers: Norwell, Dordrecht

Cuesta RA, Lovell CAK, Zofío JL 2009. Environmental efficiency measurement with translog distance functions: A parametric approach. Ecological Economics, 68: 2232-2242.

Demircan V, Binici T, Zulauf CR 2010. Assessing pure technical efficiency of dairy farms in Turkey. Agricultural Economics-Czech, 56(3): 141-148.

Estache A, Rossi MA, Ruzzier CA 2004. The case for international coordination of electricity regulation: evidence from the measurement of efficiency in South America. Journal of Regulatory Economics, 25(3): 271-295.

Food and Agriculture Organization 2009. FAOSTAT, Production Statistics. From <http://faostat.fao. org/site/567/default.aspx\#ancor> (Retrieved April 24, 2009).

Hailu A, Veeman TS 2000. Environmentally sensitive productivity analysis of the Canadian pulp and paper industry, 1959-1994: An input distance function approach. Journal of Environmental Economics and Management, 40: 251-74.

Haji J 2006. Production efficiency of smallholders' vegetable-dominated mixed farming system in eastern Ethiopia: A non-parametric approach. Journal of African Economies, 16(1): 1-27.

Herrero I 2005. Different approaches to efficiency analysis: An application to the Spanish trawl fleet operating in Moroccan water. European Journal of Operational Research, 167: 257-271.

International Institute of Tropical Agriculture 2004. 2001-2003 Nigeria Food Consumption and $\mathrm{Nu}$ trition Survey (NFCNS). From <http://www. iita. org/cms/details/Executive\%20 Summary\%20 latest.pdf $>$ (Retrieved June 10, 2009).

Irz X, Thirtle C 2004. Dual technological development in Botswana agriculture: A stochastic input distance function approach. Journal of Agricultural Economics, 55(3): 455-478.

Jaforullah M, Premachandra E 2004. Sensitivity of Technical Efficiency Estimates to Estimation Approaches: An Investigation Using New Zealand Dairy industry data. Paper presented at the AsiaPacific Productivity Conference, Brisbane, Australia, July 14 to $16,2004$.

Karagiannis G, Katranidis SD, Tzouvelekas V 2000. Measuring technical, allocative and cost efficiencies of seabass and seabream farms in Greece. Aquaculture Economics and Management, 4(3): 191-207.

López VHM, Bravo-Ureta BE, Arzubi A, Schilder E 2006. Multi-output technical efficiency for Argentinean dairy farms using stochastic production and stochastic distance frontiers with unbalanced panel data Economía Agraria, 10: 97-106.

Lundvall K, Battese GE 2000. Farm size, age and efficiency: Evidence from Kenyan manufacturing firms. The Journal of Development Studies, 36(3): 146-163. 
Mariano MJ, Villano R, Fleming E, Acda R 2010. Meta Frontier Analysis of Farm-level Efficiencies and Environmental-Technology Gaps in Philippine Rice Farming. Paper presented at the Australian Agricultural and Resource Economics Society 54th Annual Conference, Adelaide, Australia, February 10 to 12,2010 .

Morrison-Paul CJ, Johnston, WE, Frengley, GAG 2000. Efficiency in New Zealand sheep and beef farming: The impacts of regulatory reform. The Review of Economics and Statistics, 82(2): 325-337.

Msuya EE, Hisano S, Nariu T 2008. Explaining Productivity Variation among Smallholder Maize Farmers in Tanzania. From <http://mpra.ub.unimuenchen.de/14626/> (Retrieved March 10, 2009).

Muhammad I J 2009. Efficiency Analysis of CottonWheat and Rice-Wheat Systems in Punjab, Pakistan. Ph.D Thesis, Unpublished. Faisalabad: University of Agriculture. From < http://prr.hec.gov. pk/Thesis/36S.pdf> (Retrieved January 12, 2010).

Ogundari K, Ojo SO, Ajibefun IA 2006. Economies of scale and cost efficiency in small scale maize production: Empirical evidence from Nigeria. Journal of Social Science, 13(2): 131-136.

Ogunyinka EO, Ajibefun IA 2004. Determinants of technical inefficiency on farm production: Tobit analysis approach to the NDE farmers in Ondo State, Nigeria. International Journal of Agriculture and Biology, 2: 355-358.

Oyekale AS, Idjesa E 2009. Adoption of improved maize seeds and production efficiency in Rivers State,
Nigeria. Academic Journal of Plant Sciences, 2(1): 44-50.

Oyewo IO, Fabiyi YL 2008. Productivity of maize farmers' in Surulere Local Government Area of Oyo State. International Journal of Agricultural Economics and Rural Development, 1(2): 2534.

Remison SU 2005. Arable and Vegetable Crops of the Tropics. Benin City: Gift- Prints Associates.

Smith RJ, Blundell RW 1986. An exogeneity test for the simultaneous equation Tobit model with an application to labour supply. Econometrica, 54: 679-685.

Solis D, Bravo-Ureta B.E, Quiroga RE 2009. Technical efficiency among peasant farmers participating in natural resource management programmes in Central America. Journal of Agricultural Economics, 60(1): 202-219.

Umeh JC, Asogwa BC 2005. Farm Management Dividends in a Friendly Policy Environment: The Case of Cassava Industry in Nigeria. Paper presented at the $15^{\text {th }}$ IFMA Congress, Brazil, August 14 to $19,2005$.

Wadud A, White B 2000. Farm household efficiency in Bangladesh: A comparison of stochastic frontier and DEA methods. Applied Economics, 32(13): 1665-1673

Zavale H, Mabaya E, Christy R 2006. Smallholders' Cost Efficiency in Mozambique: Implications for Improved Maize Seed Adoption. Paper presented at the International Association of Agricultural Economists Conference, Gold Coast, Australia, August 12 to 18, 2006. 